\title{
ANALISIS COST-EFFECTIVENESS PENGGUNAAN SEFTRIAKSON DAN SEFOTAKSIM PADA TERAPI \\ PROFILAKSIS APENDEKTOMI DI RS PKU \\ MUHAMMADIYAH YOGYAKARTA \\ TAHUN 2006- 2007
}

\section{COST EFFECTIVENESS ANALYSIS OF CEFRIAXON AND CEFOTAXIM UTILIZATION ON APPENDEXTOMI PROFILAXIS THERAPY IN PKU MUHAMMADIYAH YOGYAKARTA IN 2006-2007 PERIOD}

\author{
Sri Aisyah Muhartati, Muhammad Muhlis, Woro Supadmi \\ Fakultas Farmasi Universitas Ahmad Dahlan \\ Jl. Prof. Dr. Soepomo, Janturan, Yogyakarta
}

\begin{abstract}
Abstrak
Telah dilakukan penelitian analisis cost-effectiveness penggunaan seftriakson dan sefotaksim pada terapi profilaksis apendektomi di RS PKU Muhammdiyah Yogyakarta periode Januari 2006-Desember 2007. Penelitian ini dilakukan untuk mengetahui direct medical cost, cost-effectiveness ratio, dan untuk mengetahui obat yang lebih cost-effective seftriakson atau sefotaksim ditinjau dari perspektif rumah sakit.Penelitian ini merupakan penelitian deskriptifyang bersifat retrospektif. Populasi penelitian ini adalah semua pasien rawat inap apendektomi yang memperoleh terapi profilaksis dengan seftriakson atau sefotaksim di RS PKU Muhammadiyah Yogyakarta. Populasi target penelitian ini adalah pasien rawat inap apendektomi yang memperoleh terapi profilaksis dengan seftriakson atau sefotaksim di kelas III RS PKU Muhammadiyah Yogyakarta pada bulan Januari 2006-Desember 2007. Hasil dari penelitian ini menunjukkan direct medical cost pada pasien yang memperoleh terapi seftriakson adalah Rp.422.257, sedangkan yang memperoleh terapi sefotaksim adalah Rp.487.680. Cost-effectiveness ratio pada pasien yang memperoleh terapi seftriakson adalah Rp.105.564 per hari, sedangkan yang memperoleh terapi sefotaksim adalah Rp.162.560 per hari. Belum dapat menentukan obat mana yang lebih cost-effective.
\end{abstract}

Kata kunci : analisis cost-effectiveness, seftriakson, sefotaksim, antibiotika profilaksis apendektomi 


\section{Abstract}

Cost-effectiveness analysis of ceftriaxone and cefotaxim prophylactic antibiotics of appendectomy in PKU Muhammadiyah Hospital Yogyakarta from January 2006 to December 2007 has been studied. This study was aimed to explore the direct medical cost, cost-effectiveness ratio, and determine whether drugs of ceftriaxone or cefotaxim whose had more effective cost. This study was carried out by descriptive retrospective design. The population was all inpatients of appendectomy getting prophylaxis antibiotics with either ceftriaxon or cefotaxim therapy in PKU Muhammadiyah Hospital Yogyakarta. The population target were the appendectomy patients in the third class of PKU Muhammadiyah Hospital Yogyakarta from January 2006 to December 2007.The result indicated that direct medical cost of the patients getting ceftriaxone therapy was $R p$ 422.257, whereas the cost of the patients getting cefotaxim therapy was $R p$ 487.680. Cost-effectiveness ratio of whom getting ceftriaxone therapy was $R p$ 105.564/day, whereas the ratio of whom getting cefotaxim therapy was $R p$ 162.560. Finally, it have not been able to determine which drug is more cost-effective.

Keywords : Cost-effectiveness analysis, ceftriaxone, cefotaxim, prophylactic antibiotics, appendectomy.

\section{PENDAHULUAN}

Hasil survey pada tahun 2008 Angka kejadian appendiksitis di sebagian besar wilayah Indonesia hingga saat ini masih tinggi. Di Indonesia, jumlah pasien yang menderita penyakit apendiksitis berjumlah sekitar $7 \%$ dari jumlah penduduk di Indonesia atau sekitar 179.000 orang. Dari hasil Survey Kesehatan Rumah Tangga (SKRT) di Indonesia, apendisitis akut merupakan salah satu penyebab dari akut abdomen dan beberapa indikasi untuk dilakukan operasi kegawatdaruratan abdomen. Insidens apendiksitis di Indonesia menempati urutan tertinggi di antara kasus kegawatan abdomen lainya (Depkes 2008)

Terjadinya apendiksistis, diduga akibat penyumbatan lumen apendiks oleh fecalith (kotoran yang mengeras), parasit, pembesaran folikel limfoid dan lain-lain (Santracroce, 2005). Gejala yang sudah menjadi ciri khas dari apendiksitis ini adalah meningkatnya nyeri abdomen yang parah. (Hardin, 1995). Pemberian obat-obatan tidak dapat menyembuhkan apendiksitis dan hanya apendektomi (operasi pemotongan dan pengeluaran apendiks yang mengalami inflamasi) yang dapat menyembuhkan apendisitis. Bedah apendektomi merupakan jenis pembedahan darurat abdomen yang paling sering dilakukan di negara barat (Anonim, 1990).

Antibiotika merupakan jenis obat yang paling banyak digunakan sebagai profilaksis bedah (Anonim, 1990). Penggunaan antibiotika profilaksis yang diberikan menurut aturan tertentu 
diharapkan dapat meminimalkan kemungkinan munculnya mikroba resisten serta dapat mengendalikan kumankuman pada daerah target operasi (Anonim, 2004). Pencegahan infeksi pada apendiksitis dapat digunakan sebagai pilihan pertama adalah kombinasi antibiotika ampisilin, klindamisin, dan gentamisin (Tucker, 2004), atau kombinasi ampisilin, gentamisin, dan metronidazol. Alternatif antibiotika kedua, yaitu kombinasi antara ampisilin dan sulbaktam, golongan sefalosporin generasi kedua (sefoksitin atau sefotetan, atau kombinasi keduanya), salah satu dari golongan sefalosporin generasi ketiga (seftriakson, sefotaksim) diberikan sendiri atau dikombinasikan dengan metronidazol, piperacilin dan tazobactam, ticarcilin dan klavulanat, atau imipenem dan silastatin, yang masing-masing diberikan secara intra vena atau intra muskulus. (Tucker, 2004).

Masalah biaya kesehatan (rumah sakit, dokter, obat, dan lain-lainnya) sejak beberapa tahun terakhir telah banyak menarik perhatian, tidak hanya di dalam negeri, tetapi juga di luar negeri (Sulastomo, 2000). Untuk mengalokasikan sumber daya yang tersedia, perlu dilakukan analisis ekonomi yang terkait dengan pelayanan kesehatan yaitu Cost-Minimization Analysis, CostEffectiveness Analysis, Cost-Utility Analysis, Cost-Benefit Analysis (Tjiptoherianto dan Soesetyo, 1994).

Mengingat tidak semua manfaat dapat diukur atau dinilai dengan uang, maka beberapa macam program di sektor kesehatan, sukar untuk dianalisis berdasarkan cost-benefit analysis. Costeffectiveness merupakan alat bantu dalam menganalisis program-program tersebut sebelum diputuskan alternatif mana yang akan dipilih (Tjiptoherianto dan Soesetyo, 1994).

Di RS PKU Muhammadiyah berbagai macam antibiotika digunakan untuk terapi profilaksis bedah apendiktomi. Jenis antibiotika yang paling sering digunakan adalah adalah seftriakson dan sefotaksim. Dari penggunaan antibiotika yang berbeda mengakibatkan besarnya biaya obat yang dikeluarkan pasien bervariasi. Sehingga perlu dilakukan penelitian untuk mengetahui terapi mana yang paling costeffective antara penggunaan seftriakson dan sefotaksim pada kasus terapi profilaksis bedah apendiktomi. Metoda analisis yang dapat digunakan adalah analisis farmakoekonomi dengan pendekatan analisis cost-effective ditinjau dari perspektif rumah sakit.

\section{METODE PENELITIAN}

\section{A. Rancangan Penelitian}

Penelitian ini dirancang secara non eksperimental (deskriptif) dengan membandingkan direct medical cost terapi dari seftriakson dan sefotaksim pada terapi profilaksis apendektomi dengan perspektif rumah sakit (institusi). Sumber data dalam penelitian adalah informasi data pasien yang berasal dari catatan medis (medical record) dan catatan keuangan pada pasien bedah apendektomi yang menjalani rawat inap di kelas III RS PKU Muhammadiyah Yogyakarta periode 2006-2007. 


\section{B. Definisi Operasional Variabel}

1. Cost-Effectiveness Ratio adalah berapa besarnya unit cost atau costeffectiveness ratio terhadap penggunaan seftriakson maupun sefotaksim pada apendektomi.

Cost-effectiveness ratio dapat diperoleh dari rata-rata direct medical cost per pasien dibagi lama hari rata-rata rawat inap masing-masing kelompok. Direct medical cost meliputi biaya pengobatan, biaya perawatan, dan biaya laboratorium.

2. Cost pada penelitian ini adalah direct medical cost. Direct medical cost yaitu seluruh biaya yang telah dikeluarkan pasien terkait dengan pelayanan jasa medis untuk terapi profilaksis apendektomi. Biaya tersebut meliputi biaya pengobatan (terdiri dari biaya obat), biaya perawatan (terdiri dari biaya visite, jasa perawatan dan biaya pengguna- an fasilitas perawatan) serta biaya laboratorium. Biaya tersebut dapat diperoleh di bagian keuangan rumah sakit.

Biaya ini dapat dihitung dengan menjumlahkan biaya pengobatan, biaya perawatan, serta biaya pemeriksaaan laboratorium kemudian dibagi jumlah kasus.

3. Efektifitas dalam penelitian ini adalah lama hari perawatan. Lama hari rata-rata rawat inap per obat, diperoleh dari jumlah hari rawat inap seluruh pasien yang menggunakan seftriakson maupun sefotaksim.

4. Antibiotika profilaksis adalah pemberian antibiotika yang diberikan sebelum operasi atau segera saat operasi pada kasus yang secara klinis tidak didapatkan tanda-tanda nyata adanya infeksi. Antibiotika profilaksis yang digunakan dalam penelitian ini adalah seftriakson dan sefotaksim.

5. Pasien yang menggunakan obat seftriakson dan sefotaksim adalah pasien yang didiagnosa apendiksitis akut.

6. Apendektomi adalah jenis pasien yang menjalani apendektomi.

\section{Populasi Target dan Populasi}

Populasi dalam penelitian ini adalah semua pasien rawat inap apendektomi yang menggunakan seftriakson atau sefotaksim di RS PKU Muhammadiyah Yogyakarta.

Populasi target dalam penelitian ini adalah pasien rawat inap apendektomi yang menggunakan seftriakson dan sefotaksim di kelas III RS PKU Muhammadiyah Yogyakarta periode 2006-2007.

Pertimbangan yang menjadi dasar pengambilan populasi, yaitu :

1. Kriteria inklusi

Apendiksitis (ICD K37), apendiksitis dengan perforasi, (ICD K35.0). Apendisitis dengan peritoneal abscess (ICD K35.1), apendiksitis akut (ICD K35.9). Pasien yang menjalani rawat inap di kelas III. Pada terapi menggunakan antibiotika seftrikson dan sefotaksim. Pasien yang pulang jika dinyatakan sembuh. 


\section{Kriteria eksklusi}

Kriteria eksklusi adalah pasien bedah apendiks yang menggunakan terapi profilaksis yang menggunakan lebih dari satu jenis antibiotika.

\section{Cara Pengumpulan Data}

Teknik pengumpulan data menggunakan teknik observasi dengan mencatat data-data yang dibutuhkan untuk penelitian. Pengumpulan data dilakukan dengan mengambil data dari bagian rekam medis dan bagian keuangan RS PKU Muhammadiyah Yogakarta, menggunakan lembar pengumpulan data.

Data pasien yang dicatat pada lembar pengumpulan data yang diambil dari bagian rekam medis meliputi nomor rekam medis, usia pasien, alamat pasien, tanggal masuk dan keluar, kondisi umum, diagnosis dokter, hasil laboratorium, dan data biaya pasien diperoleh dari bagian keuangan meliputi perincian biaya yang dikeluarkan oleh pasien.

\section{E. Analisis Data}

Data yang diperoleh meliputi biaya pengobatan, biaya perawatan, dan biaya laboratorium. Dari data tersebut, dapat dihitung variabel yaitu direct medical cost. Direct medical cost digunakan untuk mengetahui biaya yang dikeluarkan pada penggunaan antibiotika profilaksis baik dengan seftriakson maupun sefotaksim.

Besarnya direct medical cost per pasien dari masing-masing antibiotika dihitung, kemudian ditentukan besarnya cost-effectiveness ratio dari masingmasing antibiotika.

\section{HASIL DAN PEMBAHASAN}

Penelitian ini dilakukan untuk membandingkan cost-effectiveness penggunaan seftriakson dan sefotaksim pada terapi profilaksis apendektomi di RS PKU Muhammadiyah Yogyakarta, sehingga dapat diketahui pengobatan yang lebih cost-effective antara penggunaan seftriakson dan sefotaksim dengan perspektif rumah sakit. Data yang diperlukan berdasarkan data medical record di RS PKU Muhammadiyah Yogyakarta periode 2006-2007.

Tahap pengambilan data pada penelitian ini diawali dengan mengambil data secara keseluruhan penderita apendisitis yang menjalani rawat inap pada tahun 2006-2007. Kasus apendiksitis yang tercatat di bagian rekam medis bulan Januari 2006Desember 2007, berjumlah 303 kasus. Kemudian diseleksi, diambil pasien yang menjalani rawat inap di bangsal kelas III yaitu sebanyak 126 kasus. Berdasarkan kriteria inklusi dan eksklusi diperoleh 34 kasus, kemudian diseleksi lebih lanjut berdasarkan kelengkapan informasi yang ada sehingga diperoleh 12 kasus terapi profilaksis apendektomi dengan perincian 4 kasus yang memperoleh terapi seftriakson, serta 8 kasus yang memperoleh terapi sefotaksim.

\section{Profil Penggunaan Obat}

Diagnosa yang digunakan pada penelitian ini adalah apendiksitis akut. Hal ini disebabkan karena penggunaan antibiotika profilaksis pada pasien apendektomi bersifat tunggal.

Pada kasus terapi profilaksis pada apendiktomi yang memperoleh terapi 
seftriakson terdapat 4 kasus yang dapat dilihat pada Tabel I.
Pemberian asam mefenamat dan metamizol $\mathrm{Na}$ untuk menghilangkan

Tabel I. Data pasien penggunaan seftriakson pada terapi profilaskis apendektomi di RS PKU Muhammadiyah Yogyakarta periode 2006-2007

\begin{tabular}{|c|c|c|c|c|c|}
\hline No & No RM & $\underset{\text { Umur }}{\text { Utahun) }}$ & \multicolumn{2}{|r|}{ Obat } & Lama hari \\
\hline 1. & 412802 & 36 & $\begin{array}{l}1 . \\
2 . \\
3 . \\
4 . \\
5 .\end{array}$ & $\begin{array}{l}\text { Seftriakson } \\
\text { Asam mefenamat } 500 \mathrm{mg} \\
\text { Infus KAEN } \\
\text { Metamizol Na } \\
\text { Ringer Laktat }\end{array}$ & 3 hari \\
\hline 2. & 397699 & 25 & $\begin{array}{l}1 . \\
2 . \\
3 . \\
4 .\end{array}$ & $\begin{array}{l}\text { Seftriakson } \\
\text { Asam mefenamat } 500 \mathrm{mg} \\
\text { Cimetidin } \\
\text { Ringer laktat }\end{array}$ & 6 hari \\
\hline 3. & 400346 & 21 & $\begin{array}{l}1 . \\
2 . \\
3 .\end{array}$ & $\begin{array}{l}\text { Seftriakson } \\
\text { Asam mefenamat } \\
\text { Ringer laktat }\end{array}$ & 2 hari \\
\hline 4. & 421535 & 17 & $\begin{array}{l}1 . \\
2 . \\
3 . \\
4 .\end{array}$ & \begin{tabular}{|l} 
Seftriakson \\
Infus KAEN \\
Metamizole Na \\
Ringer laktat
\end{tabular} & 3 hari \\
\hline
\end{tabular}

Pada Tabel I, penggunaan seftriakson sebagai antibiotika profilaksis bagi pasien apendektomi. Asam mefenamat dan metamizol $\mathrm{Na}$ untuk menghilangkan nyeri, cimetidin sebagai $\mathrm{H}_{2}$-bloker berfungsi menghambat sekresi asam lambung. Untuk meminimalkan hilangnya cairan dilakukan pemberian infuse KAEN dan ringer laktat.

Pada kasus terapi profilaksis pada apendektomi yang memperoleh terapi sefotaksim terdapat 8 kasus yang dapat dilihat pada Tabel II.

Pada Tabel II, penggunaan sefotaksim sebagai antibiotika profilaksis bagi pasien apendektomi. nyeri. Remopain (Ketorolac tromethamine) sebagai terapi jangka pendek untuk nyeri akut, cimetidin sebagai H2-bloker berfungsi menghambat sekresi asam lambung. Domperidone sebagai antagonis dopamine berfungsi mencegah mual muntah. Untuk meminimalkan hilangnya cairan dilakukan pemberian infuse KAEN dan ringer laktat.

\section{Biaya yang Dibutuhkan}

Biaya yang dibutuhkan dalam penelitian ini berupa direct medical cost per pasien, rata-rata lama hari rawat inap dan ratio cost-effectiveness. 
Tabel II. Data pasien penggunaan sefotaksim pada terapi profilaskis apendektomi di RS PKU Muhammadiyah Yogyakarta periode 2006-2007

\begin{tabular}{|c|c|c|c|c|c|}
\hline No & No RM & Umur (tahun) & & Obat & $\begin{array}{l}\text { Lama hari } \\
\text { rawat inap }\end{array}$ \\
\hline 1. & 0409252 & 29 & $\begin{array}{l}1 . \\
2 . \\
3 . \\
4 .\end{array}$ & $\begin{array}{l}\text { Sefotaksim } \\
\text { Asam mefenamat } \\
\text { Infus KAEN } \\
\text { Ringer laktat }\end{array}$ & 4 \\
\hline 2. & 0414688 & 29 & $\begin{array}{l}1 . \\
2 . \\
3 . \\
4 . \\
5 .\end{array}$ & $\begin{array}{l}\text { Sefotaksim } \\
\text { Asam mefenamat } \\
\text { Domperidone } 10 \mathrm{mg} \\
\text { Ketoprofen } 100 \mathrm{mg} \\
\text { Ringer laktat }\end{array}$ & 3 \\
\hline 3. & 0408685 & 11 & $\begin{array}{l}1 . \\
2 . \\
3 . \\
4 .\end{array}$ & $\begin{array}{l}\text { Sefotaksim } \\
\text { Asam mefenamat } 500 \mathrm{mg} \\
\text { Metamizol Na } \\
\text { Ringer laktat }\end{array}$ & 3 \\
\hline 4. & 0356507 & 24 & $\begin{array}{l}1 . \\
2 . \\
3 . \\
4 .\end{array}$ & $\begin{array}{l}\text { Sefotaksim } \\
\text { Ketoprofen } \\
\text { Remopain } \\
\text { Ringer laktat } \\
\end{array}$ & 2 \\
\hline 5. & 0404845 & 30 & $\begin{array}{l}1 . \\
2 . \\
3 . \\
4 . \\
5 .\end{array}$ & $\begin{array}{l}\text { Sefotaksim } \\
\text { Metamizol Na } \\
\text { Remopain } \\
\text { Ringer laktat } \\
\text { Valisanbe } 5 \mathrm{mg}\end{array}$ & 3 \\
\hline 6. & 0422150 & 36 & $\begin{array}{l}1 . \\
2 . \\
3 .\end{array}$ & $\begin{array}{l}\text { Sefotaksim } \\
\text { Remopain } \\
\text { Ringer laktat } \\
\end{array}$ & 4 \\
\hline 7. & 0420619 & 39 & $\begin{array}{l}1 . \\
2 . \\
3 . \\
4 .\end{array}$ & $\begin{array}{l}\text { Sefotaksim } \\
\text { Asam mefenamat } \\
\text { Cimetidin } \\
\text { Ringer laktat } \\
\end{array}$ & 4 \\
\hline 8. & 0419852 & 22 & $\begin{array}{l}1 . \\
2 . \\
3 . \\
4 .\end{array}$ & $\begin{array}{l}\text { Sefotaksim } \\
\text { Asam mefenamat } 500 \mathrm{mg} \\
\text { Remopain } \\
\text { Ringer laktat }\end{array}$ & 4 \\
\hline
\end{tabular}

Direct medical cost yang terapi profilaksis dengan seftriakson dikeluarkan pasien yang memperoleh dapat dilihat pada Tabel III. 
Tabel III. Direct medical cost penggunaan seftriakson pada terapi profilaksis apendektomi di RS PKU Muhammadiyah Yogyakarta periode Januari 2006 - Desember 2007

\begin{tabular}{|cccccc|}
\hline No RM & $\begin{array}{c}\text { Lama Perawatan } \\
\text { (hari) }\end{array}$ & $\begin{array}{c}\text { Biaya } \\
\text { Pengobatan } \\
(\mathbf{R p})\end{array}$ & $\begin{array}{c}\text { Biaya } \\
\text { Perawatan } \\
(\mathbf{R p})\end{array}$ & $\begin{array}{c}\text { Biaya } \\
\text { Laboratorium } \\
(\mathbf{R p})\end{array}$ & $\begin{array}{c}\text { Total Biaya medis } \\
\text { langsung } \\
\text { (Rp) }\end{array}$ \\
\hline 412802 & 3 & 88.848 & 225.000 & 39.500 & 353.348 \\
397699 & 6 & $103.979,84$ & 345.000 & 109.500 & $558.479,84$ \\
400346 & 2 & 128.085 & 150.000 & 39.500 & 317.585 \\
421535 & 3 & 195.117 & 225.000 & 39.500 & 459.617 \\
\hline Biaya medis langsung per pasien & & & & $422.257 \pm 109021,57$ \\
\hline
\end{tabular}

Dari Tabel III dapat dihitung rata-rata per pasien yang diperoleh dari penjumlahan biaya pengobatan, biaya perawatan, serta biaya pemeriksaaan laboratorium kemudian dibagi jumlah kasus, sehingga diperoleh rata-rata direct medical cost per pasien sebesar $\mathrm{Rp}$ 422.257.

Direct medical cost yang dikeluarkan pasien yang memperoleh terapi profilaksis dengan sefotaksim dapat dilihat pada Tabel IV. penjumlahan biaya pengobatan, biaya perawatan, serta biaya pemeriksaaan laboratorium kemudian dibagi jumlah kasus, sehingga diperoleh rata-rata direct medical cost per pasien sebesar $\mathrm{Rp}$ 487.680 .

\section{ANALISIS BIAYA}

Evaluasi dari segi analisis biaya pada penelitian ini untuk mengetahui cost-effectiveness penggunaan seftriakson dan sefotaksim pada terapi

Tabel IV. Direct medical cost penggunaan sefotaksim pada terapi profilaksis apendektomi di RS PKU Muhammadiyah Yogyakarta periode Januari 2006 - Desember 2007

\begin{tabular}{|cccccc|}
\hline No RM & $\begin{array}{c}\text { Lama Perawatan } \\
\text { (hari) }\end{array}$ & $\begin{array}{c}\text { Biaya } \\
\text { Pengobatan } \\
(\mathbf{R p})\end{array}$ & $\begin{array}{c}\text { Biaya } \\
\text { Perawatan } \\
\mathbf{( R p )}\end{array}$ & $\begin{array}{c}\text { Biaya } \\
\text { Laboratorium } \\
\mathbf{( R p )}\end{array}$ & $\begin{array}{c}\text { Total Biaya medis } \\
\text { langsung } \\
(\mathbf{R p})\end{array}$ \\
\hline 0409252 & 4 & 117.294 & 300.000 & 109.500 & 526.794 \\
0414688 & 3 & 134.834 & 225.000 & 39.500 & 399.334 \\
0408685 & 3 & 65.628 & 260.000 & 39.500 & 365.128 \\
0356507 & 2 & 262.100 & 150.000 & 39.500 & 451.600 \\
0404845 & 3 & 228.476 & 225.000 & 39.500 & 492.976 \\
0422150 & 4 & 110.820 & 300.000 & 39.500 & 450.320 \\
0420619 & 4 & $91.247,3$ & 265.000 & 209.500 & $565.747,3$ \\
0419852 & 4 & 345.040 & 265.000 & 39.500 & 649.540 \\
\hline Biaya medis langsung per pasien & & & & $487.680 \pm 92096,73$ \\
\hline
\end{tabular}

Dari Tabel IV dapat dihitung rata-rata per pasien yang diperoleh dari profilaksis apendektomi di RS PKU Muhammadiyah Yogyakarta, sehingga 
dapat diketahui pengobatan yang lebih cost-effective antara penggunaan seftriakson dan sefotaksim dengan perspektif rumah sakit. Analisis yang dilakukan dengan menghitung direct medical coct, rata-rata lama hari rawat inap, dan ratio cost-effectiveness.

\section{Cost-effectiveness}

ratio penggunaan seftriakson dan sefotaksim pada terapi profilaksis apendektomi dapat dilihat pada Tabel V.
Analisa farmakoekonomi selain direct medical cost per pasien dan lama hari rata-rata pasien rawat inap adalah cost-effectiveness ratio, yang diperoleh dari rata-rata direct medical cost per pasien dibagi lama hari rata-rata rawat inap per obat. Dari hasil perhitungan cost-effectiveness ratio pada pasien yang menggunakan terapi seftriakson diperoleh nilai sebesar Rp. 105.564/hari, sedangkan pada pasien dengan terapi

Tabel V. Perbandingan cost-effectiveness penggunaan seftriakson dan sefotaksim pada terapi profilaksis apendektomi di RS PKU Muhammadiyah Yogyakarta periode Januari 2006 - Desember 2007

\begin{tabular}{|clcc|}
\hline No & \multicolumn{1}{c}{ Macam Biaya } & Seftriakson & Sefotaksim \\
\hline 1 & Direct medical cost per pasien & Rp. $422.257 /$ kasus & Rp. 487.680/ kasus \\
2 & Lama rata-rata hari rawat inap & 4 hari & 3 hari \\
3 & Ratio cost-effectiveness & Rp. $105.564 /$ hari & Rp. $162.560 /$ hari \\
\hline
\end{tabular}

Berdasarkan Tabel V telah dilakukan analisis farmakoekonomi dengan pendekatan analisis cost effectiveness. Direct medical cost yang dikeluarkan oleh pasien dengan terapi seftriakson lebih kecil dibanding pasien dengan terapi sefotaksim. Pada pasien yang memperoleh terapi seftriakson memerlukan 4 hari, dengan biaya yang dikeluarkan sebesar Rp. 422.257, sedangkan pada pasien yang memperoleh terapi sefotaksim memerlukan waktu 3 hari dengan biaya yang dikeluarkan sebesar Rp. 487.680. Berdasarkan lama perawatan, pasien lebih cepat memperoleh kesembuhan dengan menggunakan sefotaksim. Namun, biaya yang dikeluarkan dengan terapi sefotaksim lebih besar dibandingkan biaya yang dikeluarkan dengan terapi seftriakson. Pasien dinyatakan sembuh apabila tidak terjadi infeksi dan tidak terjadi komplikasi pasca operasi. menggunakan sefotaksim sebesar Rp. 162.560/hari. Berdasarkan perhitungan cost-effectiveness dari masing-masing penggunaan antibiotika, program yang akan dipilih adalah program yang mempunyai cost-effective terendah. Dari hasil penelitian ini belum dapat menunjukkan penggunaan antara seftriakson atau sefotaksim yang lebih cost-effective. Karena selisih antara penggunaan seftriakson dan sefotaksim memiliki perbedaan yang kecil sedangkan pada seftriakson lama hari rawat inap adalah 4 hari dan pada sefotaksim adalah 3 hari. Mungkin disebabkan oleh tidak dihitung direct non medical cost, indirect non medical cost, dan opportunity cost.

Kelemahan dari penelitian ini adalah penelitian ini belum dapat digeneralisir, hal ini disebabkan karena jumlah sampel yang terlalu sedikit, variabilitas jenis dan jumlah obat, serta parameter laboratorium. Jumlah sampel 
yang sedikit karena adanya kriteria inklusi dan eksklusi sehingga hanya terdapat 12 sampel yang digunakan. Sampel tersebut terdiri dari 4 sampel pasien yang memperoleh terapi seftriakson dan 8 sampel pasien yang memperoleh terapi sefotaksim. Variabilitas jenis dan jumlah obat, serta parameter laboratorium dapat mempengaruhi perhitungan biaya, dalam hal ini belum dapat dikendalikan.

\section{KESIMPULAN}

Berdasarkan hasil penelitian dan pembahasan tentang analisis costeffectiveness penggunaan seftriakson maupun sefotaksim pada terapi profilaksis apendektomi di RS PKU Muhammadiyah Yogyakarta, dapat disimpulkan :

1. Direct medical cost per pasien yang menggunakan seftriakson adalah Rp.422.257/kasus, sedangkan pada sefotaksim sebesar Rp. 487.680/ kasus.

2. Cost-effectiveness ratio pada pasien dengan terapi seftriakson sebesar Rp.105.564/hari, sedangkan pada pasien dengan terapi sefotaksim sebesar Rp.162.560/hari.

3. Belum dapat menentukan obat mana yang lebih cost-effective.

\section{DAFTAR PUSTAKA}

Anonim, 1990, Antibiotic Guidelines (Includes Secion for General Practitioners), Health Departement of Victoria, Australia, 36,37, 82

Anonim, 1994, Pedoman Diagnosis dan Terapi, laboratorium/ UPF ilmu bedah RSUD Dr. Soetomo, Surabaya

Anonim, 2000, Kapita Selekta Kedokteran, jilid I, Edisi ketiga, media Aes Culapius, Fak Kedokteran UI, Jakarta, 65-68

Anonim, 2004, Pedoman Antibotika Profilaksis, Edisi 1, Bagian/ SMF. Obsteri-Ginekologi Fakultas Kedokteran Universitas Airlangga Rumah Sakit Umum Dr. Soetomo, Surabaya, 4-15.

Anonim, 2008, Ilmu Bedah-Appendiks, www.bedahugm.net/Bedah-Diges ti, 1 Agustus 2009

Atthobari, J., 2006, Drug Use in Population Screening, Pharmacoepidemiological and Pharmacoeconomical Aspects, Dissertation, University of Groningen.

Dipiro, J.T., Talbert, R.L., Yee, G. C., Matzke, G. R., Wells, B. G \& Posey, L. M., 2005, Pharmacotherapy Sixth Edition, McGraw Hill, United States of America.

Gardjito,W., 1990, Antibiotika Profilaksis-Prinsip Serta Permasalahannya Dalam Kumpulan Makalah Seminar Pemilihan dan Pemakaian Antibiotika dalam Klinik, Kristin E., Mustofa, Santoso B., Suryawati S., (eds), Yayasan Melati Nusantara (YMN), Yogyakarta. 22-28.

Harrison., 1995, Prinsip-prinsip Ilmu Penyakit Dalam, volume 2, EGC, Jakarta, 666 dan 680.

Katzung, B. G., 2002, Farmakologi Dasar dan Klinik, Buku 2, Edisi 8, Salemba Medika, Jakarta. 
Orion, 1997, Pharmacoeconomics Primer and Guide Introduction to Economic Evaluation, Hoesch Marion Rousell Incorporation, Virginia.

Rahmawati, Rini., 2006, Kajian Penggunaan Antibiotika Profilaksis pada Bedah Apendektomi di RS PKU Muhammadiyah Yogyakarta Periode Januari-Desember 2005, Skripsi, Fakultas Farmasi Universtas Ahmad Dahlan, Yogyakarta.

Santoso B., 1990, Peta Klasifikasi Antibiotika dan Prinsip Pemilikan Dalam Klinik, dan Kumpulan Makalah Seminar Pemilihan dan Pemakaian Antibiotika dalam Klinis, Kristin E., Mustofa Santoso B., Suryawati S., (Eds)., Yayasan Melati Nusantara (YMN), Yogyakarta, 2-17.

Sjamsuhidajat R. dan Win de Jong., 1998, Persiapan Pra Bedah, Buku Ajar Ilmu Bedah, Edisi Revisi, EGC, Jakarta, 295-299.

Sulastomo, 2003, Manajemen Kesehatan, PT. Gramedia Pustaka Utama, Jakarta.

Soeparman dan Sarwono W., 1990, Ilmu Penyakit Dalam, Jilid II, Balai Penerbit FKUI, Jakarta, 177-182.
Tjiptoherijanto P., Soesetyo, B., 1994, Ekonomi Kesehatan, Penerbit Rineka Cipta, Jakarta.

Tucker, J., 2004, Pediatric, Appendicitis, http://www.emedicine.net. Di akses tanggal 25 Febreuari 2009

Vogenberg, F.R., 2001, Introduction to Applied Pharmacoeconomics, McGraw-Hill Companies, USA.

Walker, R and Edward, C., 2003, Clinical Pharmacy and Theraupetics, 3th edition., Churchill Livingston, Sidney Toronto, 30.

Woods, R; K. Dellinger, P., 1998, Current Guidelines for Antibiotics Prophylaxis of Surgical Wound, http://www.aaff.org.

Yuliarsih T., 2004, Pola Pemakaian Antibiotika Pada Bedah Apendisitis di Instalasi Bedah RSU PKU Muhammadiyah Yogyakarta tahun 2002, Skripsi, Fakultas Farmasi Universitas Gadjah Mada, Yogyakarta. 